Canadian

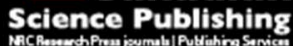

Applied Physiology, Nutrition, and Metabolism Physiologie appliquée, nutrition et métabolisme

\title{
Plyometric exercise combined with high-intensity interval training improves metabolic abnormalities in young obese females more so than interval training alone
}

\begin{tabular}{|c|c|}
\hline Journal: & Applied Physiology, Nutrition, and Metabolism \\
\hline Manuscript ID & apnm-2015-0384.R2 \\
\hline Manuscript Type: & Article \\
\hline Date Submitted by the Author: & 23-Sep-2015 \\
\hline Complete List of Authors: & $\begin{array}{l}\text { Racil, Ghazi; Departmnt of Biological Sciences, Faculty of Sciences, } \\
\text { University Tunis El Manar, Tunis, Tunisia } \\
\text { Zouhal, Hassane; Movement Sport and Health Sciences Laboratory (M2S), } \\
\text { UFR-APS, ENS-Rennes, University of Rennes } 2 \\
\text { Elmontassar, Wassim; Laboratory of Biomechanics and Biomaterials } \\
\text { Research Applied to Orthopedics, National Institute of Orthopedics, Tunis, } \\
\text { Tunisia, } \\
\text { Ben Abderrahmane, Abderraouf; Higher Institute of Sport and Physical } \\
\text { Education in Tunis, Ksar Said, University of Manouba } \\
\text { de Sousa, Maysa Vieira; Laboratory of Medical Investigation, LIM-18, } \\
\text { Medical School, University of Sao Paulo } \\
\text { Chamari, Karim; Athlete Health and Performance Research Centre, } \\
\text { Aspetar; Orthopedic and Sports Medicine Hospital } \\
\text { Amri, Mohamed; Laboratory of Functional Neurophysiology and Pathology, } \\
\text { Faculty of Sciences Tunis, Tunisia, } \\
\text { Coquart, Jeremy; Université de Rouen, Faculté des Sports, CETAPS, } \\
\text { EA4488 }\end{array}$ \\
\hline Keyword: & $\begin{array}{l}\text { obese children, intermittent exercise, strength training program, lean body } \\
\text { mass, adipocytokines }\end{array}$ \\
\hline
\end{tabular}

\section{SCHOLARONE \\ Manuscripts}




\section{Plyometric exercise combined with high-intensity interval training improves metabolic} abnormalities in young obese females more so than interval training alone (3)

${ }^{a}$ Department of Biological Sciences, Faculty of Sciences, University Tunis El Manar, Tunis, Tunisia. ${ }^{\mathbf{b}}$ Movement Sport and Health Sciences Laboratory (M2S), UFR-APS, ENS-Rennes, University of Rennes 2, Rennes, France. 'Laboratory of Biomechanics and Biomaterials Research Applied to Orthopedics, National Institute of Orthopedics, Tunis, Tunisia. ${ }^{\mathrm{d}}$ Higher Institute of Sport and Physical Education in Tunis, Ksar Said, University of Manouba,Tunisia. ${ }^{\mathrm{e}}$ Laboratory of Medical Investigation, LIM-18, Medical School, University of Sao Paulo, São Paulo, Brazil. ${ }^{\mathbf{f}}$ Athelte Health and Performance Research Centre, Aspetar, Qatar; Orthopedic and Sports Medicine Hospital, Doha, Qatar. ${ }^{\mathbf{g}}$ Centre of Transformations from Physical Activities and Sports, Faculty of Sport Sciences, University of Rouen, Mont Saint Aignan, France.

*Address correspondance to Jeremy Coquart, Faculté des Sciences du Sport et de l'Education Physique, CETAPS, boulevard Siegfried, 76821 Mont Saint Aignan Cedex, France. Phone: +33(0)232107797 - Fax: +33(0)232107793. E-mail: jeremy.coquart@voila.fr. 
27 Abstract

28 The aim of this study was to compare the effects of 12 weeks of high intensity interval 29 training (HIIT) vs plyometric exercise combined with HIIT (P+HIIT) on anthropometric, 30 biochemical and physical fitness data in young obese females. Sixty-eight participants (age: $3116.6 \pm 1.3$ y, body mass: $82.8 \pm 5.0 \mathrm{~kg}$, body fat: $39.4 \pm 3.3 \%$, body mass index $Z$-score: $2.9 \pm 0.4$ ) 32 were assigned to one of three groups: HIIT (2 blocks per session of 6-8 bouts of 30-s runs at $33100 \%$ velocity at peak oxygen uptake: $\mathrm{v} \mathrm{VO}_{2 \text { peak, }}$, with 30 -s active recovery between bouts at $3450 \% \mathrm{vV}_{2 \text { peak }} ; n=23$ ), P+HIIT ( 2 blocks per session of 3 different 15 -s plyometric exercises 35 with 15 -s passive recoveries, totaling 2 min for each plyometric exercise + the same HIIT 36 program; $n=26$ ) or control (no exercise; $n=19$ ). Anthropometric (body mass, body mass index 37 Z-score, body fat, lean body mass and waist circumference), biochemical (plasma glucose, 38 insulin, leptin and adiponectin concentrations, leptin/adiponectin ratio and homeostasis model assessment-insulin resistance: HOMA-IR), physical fitness (peak oxygen uptake, $\mathrm{vV}_{2 \text { peak, }}$ squat jump and countermovement jump performances), and energy intake data were collected.

41 Both training programs improved the anthropometric, biochemical and physical fitness 42 variables. However, the $\mathrm{P}+\mathrm{HIIT}$ program induced greater improvements than the HIIT program in lean body mass $(+3.0 \pm 1.7 \%)$, plasma glucose and leptin concentrations ($11.0 \pm 4.7 \%$ and $-23.8 \pm 5.8 \%$, respectively), plasma leptin/adiponectin ratio $(-40.9 \pm 10.9 \%)$, HOMA-IR (-37.3 $\pm 6.2 \%)$ and squat jump performance $(22.2 \pm 7.5 \%)$. Taken together, these findings suggest that adding plyometric exercises to a HIIT program may be more beneficial 47 than only HIIT in obese female adolescents.

Keywords: obese children, intermittent exercise, strength training program, lean body mass, adipocytokines. 


\section{2}

53

54

55

56

57

58

59

60

61

62

63

64

65

66

67

68

69

70

71

72

\section{Introduction}

The rising prevalence of adulthood overweight and obesity is a risk factor for many chronic diseases and death (Zhou 2002). In addition, childhood and adolescent obesity have reached unprecedented levels (Lobstein et al. 2015), and studies show that obese children and adolescents are more likely to become obese adults (Serdula et al. 1993; Witaker et al. 1997). The prevention and treatment of obesity in young people is therefore crucial.

Several strategies have been recommended to treat obesity. One of the commonest strategies is regular physical exercise. However, as Boutcher (2011) pointed out, most exercise recommendations to induce weight loss have focused on steady-state exercise (or continuous exercise). Yet the beneficial effects of this type of exercise are often disappointing over the long run because of poor program adherence. Indeed, the monotony of this type of exercise seems be an obstacle to breaking the vicious circle of the sedentary lifestyle (Coquart et al. 2008). Other types of exercise have therefore been proposed, like interval training (i.e., exercise during which the intensity varies regularly) (Coquart et al. 2008; Racil et al. 2015), which obese patients reported as being less difficult than steady-state exercise (Coquart et al. 2008). Moreover, its beneficial effects on anthropometric, physiological and physical fitness variables in obese adults were demonstrated (Coquart et al. 2008). More recently, Racil et al. (2013) compared the effects of moderate- vs high-intensity interval training (HIIT) on the anthropometric, biochemical and physical fitness variables in obese female adolescents. Their results indicated that both interval training programs had numerous beneficial effects in this age group, although anthropometric (i.e., body fat and body mass index $Z$-score: BMI $Z$ score) and biological (i.e., total cholesterol, low-density lipoprotein cholesterol and insulin concentrations) improvements were significantly better with HIIT. Therefore, HIIT can be recommended for young (Racil et al. 2013) and adult obese populations (Paoli et al. 2013). 
On the other hand, plyometric is a type of training where muscles undergo a rapid elongation followed by an immediate shortening (stretch-shortening contraction), utilizing the elastic energy stored during the stretching phase (Cavagna, 1977). It has been demonstrated that explosive-type resistance training is efficient in improving vertical jump and has been shown to improve muscle strength (Mcbride et al. 2002).

Therefore, plyometric exercise may be considered an important component of exercise programs for the obese. Russell et al. (2014) recently examined the effects of a resistance training program including plyometric exercises on fasting plasma glucose concentration. The results showed a significant decrease in glucose concentration and increased strength, which were inversely correlated $(P \leq 0.05 ; r=-0.52)$. Moreover, Shabi et al. (2006) reported that male adolescents with high obesity risk were able to significantly increase insulin sensitivity after 16 weeks of resistance training. These authors suggested indeed that the qualitative changes in skeletal muscle have contributed to this enhancement. Further, it appears that the impact of resistance training on muscle mass and strength in both young and older individuals is more pronounced with high training intensities (Fielding, 1995), which can result significant effects on insulin sensitivity (Miller et al. 1994; Ryan et al. 1996).

According to the previous studies, it has been indicated that muscle growth largely explain the disparity between sexes, especially for absolute measures of muscular strength and power (Neu et al. 2002; O'Brien et al. 2009). In this context, it is interesting to note that the sexrelated differences in muscular strength are more evident as children enter adolescence, with males consistently outperforming females (O'Brien et al. 2010). However, to the best of the authors' knowledge, no study has yet examined the effects of plyometric exercise combined with HIIT (i.e., $\mathrm{P}+\mathrm{HIIT}$ ) in the young obese population. 
101 The adipocytokines, mainly leptin and adiponectin, are biologically active proteins that are 102 significantly correlated (negatively for adiponectin) with the body mass index percentile in 103 children (Chi-Jen et al. 2015). Moreover, leptin and adiponectin have been associated with insulin resistance (Yamamoto et al. 2002), which is frequently observed in obese patients. HIIT was demonstrated to significantly decrease plasma leptin concentration (Sartor et al. 2010) and increase plasma adiponectin concentration (Racil et al. 2013). However, no study

107 has yet compared HIIT with P+HIT to determine which would be the optimal exercise 108 protocol to beneficially affect adipocytokines in the obese population. Therefore, the main

109 aim of the present study was to analyze the effects of HIIT and P+HIIT on anthropometric, 110 biochemical and physical fitness variables in obese female adolescents.

111 We hypothesized that the participants in the P+HIIT program would exhibit significantly 112 greater insulin sensitivity which decreases the plasma glucose concentration compared with 113 HIIT program.

\section{Materials and methods}

\section{Participants}

118 Seventy-five obese female adolescents, recruited from five secondary schools of the same

119 region, volunteered to take part in this study. All participants were classified according to

120 BMI which was calculated in the standard way, using the algorithm provided by the Centers

121 for Disease Control and Prevention (CDC). Firstly, BMI was calculated from following 122 equation: BMI (in $\mathrm{kg} \cdot \mathrm{m}^{-2}$ ) = body mass (in $\mathrm{kg}$ ) $\div$ height ${ }^{2}$ (in $\mathrm{m}$ ). Then, the BMI scores were 123 transformed to produce age- and sex-adjusted BMI percentiles using the CDC growth chart.

124 None of the participants was involved in systematic exercise training at the time of data 125 collection. Prior to data collection, all participants and parents provided written informed 
126 consent in accordance with the international ethical standards and the 1964 Helsinki

127 Declaration and its later amendments. This study was approved by the local research ethics 128 committee.

\section{Anthropometric measures}

131 During a preliminary session, the height of each participant was measured using a wall

132 stadiometer, and body mass and percentages of body fat and lean body mass were assessed

133 with a calibrated bioelectrical impedance scale (TBF-300, Tanita ${ }^{\circledR}$, Tokyo, Japan). As

134 recommended for children and adolescents (Rolland-Cachera et al. 1991), BMI Z-scores were

135 calculated. Waist circumference was measured at the mid-point between the bottom of the rib

136 cage and the iliac crest. All measurements were conducted on the same morning between 8:30

137 a.m. and 12:30 p.m. by the same evaluator.

\section{Biochemical analysis}

140 Twelve-hour fasting blood samples were taken from an antecubital vein before the

141 intervention program; between 7:00 and 9:00 a.m. Samples were collected and then

142 centrifuged for $15 \mathrm{~min}$ at $3000 \mathrm{rpm}$. Plasma samples were stored at $-80^{\circ} \mathrm{C}$ until assayed.

143 Plasma glucose concentration was measured by the hexokinase method using an automated

144 device (Architect c8000, Abbott ${ }^{\circledR}$, Quebec, Canada). Plasma insulin concentrations were

145 measured by radioimmunoassay kits (Immunotech A, Beckman Coulter Company ${ }^{\circledR}$,

146 Marseille, France). Insulin resistance was assessed using the homeostasis model assessment-

147 insulin resistance (HOMA-IR), computed as follows:

148 HOMA-IR $=\left[\right.$ fasting insulin $\left(\mu \mathrm{U} . \mathrm{mL}^{-1}\right) \times$ fasting glucose $\left.\left(\mathrm{mmol} . \mathrm{L}^{-1}\right)\right] \div 22.5$

149 Plasma leptin and adiponectin were evaluated in duplicate runs using an enzyme-

150 linked immunosorbent assay (ELISA) kit (Quantikine: human total adiponectin/acrp 30 
151 immunoassay and human leptin immunoassay). From these plasma concentrations, the 152 adiponectin/leptin ratio was also calculated. This ratio is important since it has been proposed 153 as biological and potential index of insulin sensitivity during growth (Koebnick et al. 2007).

\section{Physical fitness evaluation}

156 Before the intervention period, all participants performed a graded exercise test until 157 exhaustion (Cazorla, 1990). This maximal test was carried out on 200-m outdoor track

158 calibrated with cones. The test starts at a running speed of $8.5 \mathrm{~km} \cdot \mathrm{h}^{-1}$ and increases by 0.5 $159 \mathrm{~km} \cdot \mathrm{h}^{-1}$ every minute until exhaustion. During the test, respiratory gas exchange was measured 160 breath-by-breath using a calibrated portable telemetry system ( $\mathrm{K}_{4} \mathrm{~b}^{2}$, Cosmed ${ }^{\circledR}$, Rome, Italy).

161 Moreover, heart rate was monitored using a heart rate monitor (S-610, Polar ${ }^{\circledR}$, Kempele,

162 Finland). Exhaustion was verified based on the following criteria: 1) a plateau in oxygen 163 uptake, 2) respiratory exchange ratio $\geq 1.1,3$ ) peak heart rate $\pm 10 \mathrm{bpm}$ of the predicted 164 maximal heart rate (220 - age), and 4) apparent voluntary exhaustion. At least three of the

165 four criteria were met or the test was repeated. Once exhaustion was confirmed, peak oxygen 166 uptake $\left(\dot{\mathrm{VO}}_{2 \text { peak }}\right)$ and velocity at $\dot{\mathrm{V}} \mathrm{O}_{2 \text { peak }}\left(\right.$ i.e., $\left.\mathrm{v}_{\mathrm{V}} \mathrm{O}_{2 \text { peak }}\right)$ were identified.

168 The squat jump (SJ) and countermovement jump (CMJ) were performed using an infrared 169 jump system (Optojump, Microgate ${ }^{\circledR}$, Bolzano, Italy) interfaced with a microcomputer. 170 Participants were asked to perform the SJ with feet parallel and shoulder-width apart, good 171 balance in an upright position with the trunk remaining as vertical as possible, and hands on 172 the hips throughout the test with a knee angle around $90^{\circ}$. The trial was not considered valid if 173 any movement was perceived with the increased knee flexion at the start of the jump. For the 174 CMJ, participants started from an upright standing position and made a preliminary 175 downward movement by flexing the knees and hips, with a knee angle around $90^{\circ}$ at the end 
176 of the countermovement. The trial was not considered valid if the knees did not bend quickly

177 and to the maximum. The best of three trials was recorded for SJ and CMJ.

178

179 Energy intake

180 All participants completed a 4-day dietary questionnaire (3 weekdays and 1 weekend day) in

181 the week prior to the intervention program. The questionnaire responses were then analyzed

182 with Bilnut 2.01 software (Nutrisoft ${ }^{\circledR}$, Cerelles, France) to determine energy intake (kcal.day ${ }^{-}$ $\left.183^{1}\right)$.

184

185

Intervention protocol

186 After the evaluations of baseline anthropometric, biochemical, physical fitness and energy

187 intake data, the participants were randomly assigned to one of the three following groups:

188 high-intensity interval training only (HIIT group, $n=23$ ), combined plyometric exercise and

189 high-intensity interval training (P+HIIT group, $n=26)$, or no-exercise control $(n=19)$.

190

191 The high-intensity interval exercises in both training groups (i.e., HIIT and $\mathrm{P}+\mathrm{HIIT}$ ) were

192 composed of two blocks of six (in the first 4 weeks) or eight bouts of 30 -s runs at $100 \%$

193 velocity at $\dot{\mathrm{V}} \mathrm{O}_{2 \text { peak }}\left(\mathrm{v}_{\mathrm{V} O} \mathrm{P}_{\text {peak }}\right)$ with $30 \mathrm{~s}$ of active recovery between bouts at $50 \% \mathrm{v} \dot{\mathrm{V}} \mathrm{O}_{2 \text { peak }}$, on

194 an 200-m outdoor track. The two blocks were separated by a 4-min passive recovery period.

195 The exercise intensities were increased by $5 \% \mathrm{v} \dot{\mathrm{VO}} 2$ peak at the start of each consecutive 4-

196 week period. The training sessions were held 3 days per week for 12 weeks (i.e., Monday,

197 Wednesday and Friday).

198

199 In the P+HIIT group, the high-intensity interval exercises were preceded by plyometric

200 exercises. Those exercises were based on findings from previous investigations (Chu et al. 
201 2006; Myer et al. 2005). Two blocks of three different plyometric exercises : weeks 1-4:

202 double-leg jump, medicine ball overhead throw, and medicine ball single-leg dip; weeks 5-8:

203 hurdle hops, zig-zag jump drill, and medicine ball backward throw; weeks 9-12: single-leg

204 cone hops, single-leg zig-zag drill, and medicine ball partner push pass were performed in

205 each training session. It is worth noting that participants performed basic plyometric

206 movements in the first training period (weeks 1-4), which could provide the occasion to

207 participants to gain confidence in their abilities before progressing to more advanced drills at

208 second (weeks 5-8) and at the third training periods (weeks 9-12) (Myer et al. 2005). Each

209 plyometric exercise was maintained for $2 \min (15 \mathrm{~s}$ of plyometric exercise $v s 15 \mathrm{~s}$ of passive

210 recovery). Between each block and between each new exercise, the passive recovery periods

211 lasted $1 \mathrm{~min}$ and $30 \mathrm{~s}$, respectively.

212 All training sessions (HIIT and P+HIIT) started with a standardized warm-up (i.e., 10 min of 213 jogging at $50 \% \mathrm{v} \dot{\mathrm{VO}} 2$ peak and then 5 min of dynamic stretching exercises and 5 accelerations 214 over $20 \mathrm{~m}$ with $1 \mathrm{~min}$ of recovery between) and ended with a cool-down at $50 \% \mathrm{vVO}_{2 \text { peak }}$ for $21510 \mathrm{~min}$ followed by $5 \mathrm{~min}$ of static stretching. Throughout the study period and prior to each 216 test commencement, an experienced physical education teacher demonstrated the proper 217 exercise technique. All participants were consistently encouraged to maintain proper 218 technique performance for as long as possible.

\section{General information}

221 Whatever the group, all participants were instructed to maintain their usual physical activity 222 level and their usual diet. After the 12-week intervention period, all anthropometric, 223 biochemical, physical fitness and energy intake data were collected again, in the same 224 conditions and by the same evaluators. 


\section{Statistical analysis}

227 Data are reported as mean and standard deviation. The Shapiro-Wilk test was applied to

228 examine normality, whereas homogeneity of variance was assessed using Levene's test. Once 229 the assumption of normality was confirmed, parametric tests were performed. Data were 230 analyzed using a two-way analysis of variance with repeated measures (3 groups: HIIT vs

$231 \mathrm{P}+$ HIIT $v s$ control $\times 2$ times: before $v s$ after the intervention program). Whenever significant

232 differences in values occurred, a pairwise multiple comparisons test was performed using a 233 Bonferroni post-hoc test.

234 Percentage changes in the variables from pre- to post-intervention were calculated, and a one235 way ANOVA was conducted to identify the differences between groups. When data were not 236 normally distributed, the nonparametric Kruskal-Wallis test was used.

237 All statistical analysis was performed using SPSS version 20.0 (SPSS ${ }^{\circledR}$, Chicago, IL, USA). 238 The level of statistical significance was set at $P<0.05$.

\section{Results}

241 During the 12 weeks intervention period no injuries were reported but seven subjects were

242 unable to complete the training program or achieve all the tests at post-intervention for

243 personal reasons: two from (HIIT group), one from (P+HIIT group) and four from control 244 group, and their data are thus excluded from all analyses. Therefore, 68 obese female 245 adolescents (age: $16.6 \pm 1.3 \mathrm{y}$, height: $1.63 \pm 0.05 \mathrm{~m}$, body mass: $82.8 \pm 5.0 \mathrm{~kg}$, body fat: 39.4 $246 \pm 3.3 \%$, BMI Z-score: $2.9 \pm 0.4$ ) have fully completed the current study. The values of all 247 anthropometric, biochemical, and physical fitness variables and energy intake, measured 248 before and after the intervention period, are presented in Table 1. Moreover, the percentage 249 changes in these data are presented in Table 2. 
250 Significant decreases were noted in body mass, BMI Z-score, body fat and waist 251 circumference in both training groups (i.e., HIIT and P+HIIT; $P<0.05$; Table 1), but only the

$252 \mathrm{P}+$ HIIT group showed a significant increase in lean body mass $(P=0.021)$. This increase was 253 significantly different from that of the other groups $(P=0.012$; Table 2$)$.

254 The plasma glucose and insulin concentrations were significantly decreased in the HIIT and 255 P+HIIT groups after the training program, resulting in a significant decrease in HOMA-IR in 256 both groups $(P<0.05$; Table 1$)$. The decreases in plasma glucose concentration and HOMA257 IR were significantly greater in the $\mathrm{P}+\mathrm{HIIT}$ group than in the other groups $(P<0.05$; Table 258 2). The HIIT and P+HIIT groups also showed a significant decrease in plasma leptin 259 concentration ( $P=0.033$ and $P=0.019$, respectively) and an increase in plasma adiponectin 260 concentration $(P=0.029$ and $P=0.012$, respectively; Table 1). Moreover, the plasma 261 leptin/adiponection ratio was significantly reduced in both training groups $(P<0.01$; Table $2621)$.

263 In the between-group comparison, P+HIT showed a significant decrease in plasma leptin 264 concentration and the plasma leptin/adiponection ratio, which were greater than in the other 265 groups $(P<0.05$; Table 2$)$.

$266 \dot{\mathrm{V}} \mathrm{O}_{2 \text { peak }}, \mathrm{v} \dot{\mathrm{V}} \mathrm{O}_{2 \text { peak }}$ and $\mathrm{SJ}$ and $\mathrm{CMJ}$ performances were significantly increased in both trained 267 groups $(P<0.05$; Table 1$)$. The improvement in SJ was significantly greater in the P+HIIT 268 group compared with the other groups $(P=0.035$ Table 2$)$.

269 No significant change in energy intake was noted in any group $(P>0.05$; Tables 1 and 2$)$.

\section{Discussion}

272 The main aim of the present study was to analyze the effects of HIIT and P+HIIT on 273 anthropometric, biochemical and physical fitness data in obese female adolescents. The 274 results indicate that 12 weeks of HIIT or $\mathrm{P}+\mathrm{HIIT}$ training (without dietary restriction) 
275 improved these data in the adolescents (Table 1). However, the P+HIIT program induced 276 significantly greater improvements in lean body mass, plasma glucose and leptin 277 concentrations, HOMA-IR, the plasma leptin/adiponectin ratio and SJ performance (Table 2). 278

279 According to numerous studies (Boutcher 2011; Paoli et al. 2013; Racil et al. 2013), HIIT 280 (with or without plyometric exercises) is especially efficient to reduce body mass and fat in 281 the obese population. Consequently, adding to the fact that this training modality increases 282 insulin sensitivity (Racil et al. 2013), the plyometric exercises place significant stress on the 283 musculoskeletal system (Fowler et al. 1995). It is important to mention that following intense 284 exercises, a metabolic stress on active muscle fibers occurs, leading to increases in glucose 285 uptake resulting in enhanced insulin sensitivity (DiPietro et al. 2006; Rose and Richter, 2005).

However, to increase lean body mass, the recommendation is to associate HIIT with resistance exercises (Table 2). Some authors have suggested that aerobic exercise is the

289 optimal training mode to reduce body mass and fat, whereas a training program including 290 resistance exercise (such as plyometric exercises) is advised to increase lean body mass 291 (Ghahramanloo et al. 2009; Willis et al. 2012). Thus, to further increase the beneficial effects 292 of HIIT on lean body mass, resistance exercise should be associated (Table 2). This latter type 293 of exercise is essential because it increases muscle mass, and skeletal muscle is the major site 294 of insulin-stimulated glucose utilization in the body (Joseph and Hood, 2014). Indeed, an 295 increase in muscle mass suggests an enhanced number of mitochondria, which improves the 296 ability of muscle to oxidize substrates (i.e., glucose and free fatty acids), thus reducing plasma 297 glucose concentration, which we suppose was the case in our study in the P+HIT group. In 298 fact, results have shown that glucose concentration was significantly lower in the P+HIIT 299 group compared with the HIIT and control groups (Table 2). In the same context an increase 
300 in muscle mass suggests also an enhanced free fatty acid concentration and insulin resistance

301 as shown in our study with a significantly lower HOMA-IR in the P+HIIT group (Table 2).

302 This may prevent complications linked to obesity (e.g., metabolic syndrome, type 2 diabetes, 303 myocardial infarction).

304

305 Furthermore, it is likely that the greater effect on insulin sensitivity may be the result of type 306 of training (i.e., $\mathrm{P}+\mathrm{HIIT}$ ) and the intensity which induces the metabolic responses that

307 predominantly depend on carbohydrates as the main fuel source (i.e., phosphocreatine and 308 anaerobic glycolysis systems). In fact, other studies have demonstrated that resistance training

309 at high intensity was safe and well tolerated by older patients with type 2 diabetes, was

310 effective in improving glycemic control (Dunstan et al. 2002), and has improved insulin 311 action in healthy young women (Poehlman et al. 2000).

313 On the other hand, leptin and adiponectin, two hormones secreted by adipocytes, are counter-

314 regulated in vivo and exert opposing effects on glucose metabolism, fat oxidation, and insulin 315 sensitivity (Ceddia 2005; Yamauchi et al. 2002). In this context, some authors have proposed 316 the leptin/adiponectin ratio as a potential marker for the comorbidities of childhood obesity 317 (Diamond et al. 2004). More recently, this hypothesis seems to have been confirmed because 318 the number of metabolic syndrome alterations was found to be correlated with the 319 leptin/adiponectin ratio in obese adolescents (Masquio et al. 2015). We therefore assume that 320 the significant decrease in this ratio in the present study indicated an improvement in the 321 health status of our obese female adolescents after participation in an interval training 322 program, and this was remarkably so in the P+HIIT group (Table 2). 
324 The significantly greater decrease in the leptin/adiponectin ratio in the P+HIT group seemed 325 mainly linked to a significantly greater reduction in the plasma leptin concentration (Table 2).

326 This latter decrease is important in obesity treatment because leptin increases the rate of 327 insulin-stimulated glucose uptake and glucose oxidation, and normalizes the rate of glycogen 328 synthesis (Yaspelkis et al. 2004), thus suggesting a reduction in plasma glucose concentration 329 (which decreased more in the P+HIIT group than the HIIT group; Table 2). Theoretically, 330 these responses might be due in part to the normalization of glucose transporter type-4 protein 331 (GLUT4) concentration in the muscle (Yaspelkis et al. 2004). However, since Donges et al. 332 (2013) recently showed an increase in insulin sensitivity after a training program (i.e., aerobic 333 and/or resistance exercise) and did not note a change in GLUT4 muscle content in untrained 334 middle-aged men, further studies are needed to better understand the mechanisms linked to 335 the reduction in plasma glucose concentration in obese adolescents.

337 After the intervention period, HOMA-IR was reduced to $3.2 \pm 0.4$ and $2.7 \pm 0.3$ in the HIIT 338 and P+HIIT groups, respectively (Table 1). The HOMA-IR cut-off point for a diagnosis of 339 insulin resistance was reported to be 3.16 in adolescents (Keskin et al. 2005). As such 14 (i.e., $34060.8 \%$ ) and 23 (i.e., 88.5\%) adolescents were below this threshold value after the HIIT and $341 \mathrm{P}+\mathrm{HIIT}$ programs, respectively. According to present results, it seems that this training 342 modality (i.e., P+HIIT) can provide an opportunity for all youth, regardless of body mass and 343 fitness level, to experience success and feel good about their body. On the other hand, as 344 overweight/obese children and adolescents seem to demonstrate significantly lower motor 345 coordination than youth with 'normal' body mass index (D'hondt et al. 2011; Nunez-Gaunaurd 346 et al. 2013), it is possible that HIIT associated to coordination exercises and/or conventional 347 resistance exercise would provide higher benefits to $\mathrm{P}+\mathrm{HIIT}$. Therefore, an additional work is 348 also required to assess even more the appropriateness of such programs for obese female 
349

350

351 While both training groups (i.e., HIIT and P+HIIT) improved SJ and CMJ performances

352 (Table 1), SJ improvement was greater in the P+HIIT group (Table 2). Recently, Russell et al.

353 (2014) showed strength improvement after a resistance training program including plyometric

354

355

356

357

358

359

360

361

362

363

364

365

366

367

368

369

370

371

372

373

adolescents.

exercise. Moreover, the authors reported that the strength changes were inversely correlated with fasting plasma glucose concentration. The current study also suggests this because both variables were significantly higher in the P+HIIT group than in the other groups (Table 2).

Consequently, to optimize strength gains, it seems necessary to include resistance exercises in interval training programs.

Last, Coquart et al. (2008) proposed interval training as a way to increase adherence to exercise programs and limit the monotony of steady-state exercise (or continuous exercise), which is frequently offered in intervention programs. However, it now remains to be seen whether the $\mathrm{P}+\mathrm{HIIT}$ program confers more long-term adherence benefits for obese female adolescents than HIIT alone.

Some limitations of this study are acknowledged. Firstly, cycling rather than running on the track may be a more appropriate exercise modality, given orthopaedic issues that may occur in obese population. However, the running exercise may be performed without ergometer and thus in the daily life.

On the other hand, since the sex-related (anthropometric and physiological) differences begin from the adolescence, and since the boys spend more time in physical exercise with vigorousor moderate-intensity than girls (Belsky et al. 2003), we opted in the current study to focus only on obese adolescent females in order not to have any confounding effects of sex on the collected results. Further study in obese male adolescents would also be useful. 


\section{Conclusion}

375 The current study findings demonstrate that the HIIT appears to be an efficient strategy to 376 combat obesity. Moreover, as HIIT is less monotonous (because of intensity variation) than 377 traditional aerobic exercise (in which the exercise intensity is continuous), HIIT may be 378 recommended to improve the adherence in training program. Furthermore, to optimize the 379 taking over, $\mathrm{P}+\mathrm{HIIT}$ must be preferred to only HIIT. Indeed, this training modality produces 380 better physiological adaptations (e.g., management of glycemic control) than HIIT in obese

381 female adolescents. Additional studies are nevertheless needed to elucidate the mechanisms of 382 these specific adaptations.

Acknowledgments: The current study was supported by the Ministry of Higher Education, Scientific Research and Technology of Tunisia. We would like to thank the medical staff for their medical assistance. We would also like to thank the physical education teachers who guided us to the obese participants, without whom this work would not have been possible.

Conflict of interest: The authors have no conflict of interest to declare.

\section{References}

Belsky, J.C., Booth, R., Bradley, C.A., Brownell, S.B., Campbell, A., Clarke-Stewart, S.L., et al. 2003. Frequency and intensity of activity of third-grade children in physical education. Arch. Pediatr. Adolesc. Med. 157(2):185-190. doi:10.1001/ archpedi. 157.2.185.

397 Cavagna G. 1977. Storage and utilization of elastic energy in skeletal muscle. Exerc. Sports. Sci. Rew. 5(1): 89-129. doi: 10.1249/00003677-197700050-00004. 
Cazorla G. 1990. Test de terrain pour évaluer la capacité aérobie et la vitesse aérobie maximale. In: « Actes du colloque international de la Guadeloupe ». Eds: ACTSCHNG \& AREAPS. 151-173.

Ceddia, R.B. 2005. Direct metabolic regulation in skeletal muscle and fat tissue by leptin: implications for glucose and fatty acids homeostasis. Int. J. Obes. 29(10):1175-83. doi:10.1038/sj.ijo.0803025

Chi-Jen, C., Deng-Yuan, J., Ming-Wei, L., Jun-Zhi, Z., Low-Tone, H., Chi-Chang J. 2015. Evidence in Obese Children: Contribution of Hyperlipidemia, Obesity-Inflammation, and Insulin Sensitivity. PLoS One. 10(5): e0125935. doi: 10.1371/ journal.pone.0125935. eCollection 2015.

Chu, D., Faigenbaum, A., Falkel, J. 2006. Progressive plyometrics for kids. Monterey, CA: Healthy Learning.

Coquart, J.B., Lemaire, C., Dubart, A.E., Luttembacher, D.P., Douillard, C., Garcin, M. 2008. Intermittent versus continuous exercise: effects of perceptually lower exercise in obese women. Med. Sci. Sports. Exerc. 40 (8): 1546-1553. doi: 10.1249/MSS.0b013e31816fc30c.

D'hondt, E., Deforche, B., Vaeyens, R., Vandorpe B, Vandendriessche, J., Pion, J., et al. 2011. Gross motor coordination in relation to weight status and age in 5- to 12-yearold boys and girls: a cross sectional study. Int. J. Pediatr. Obes. 6(2): e556-64. doi: $10.3109 / 17477166.2010 .500388$.

Diamond, F.B., Cuthbertson, D., Hanna S., Eichler, D. 2004. Correlates of adiponectin and the leptin/adiponectin ratio in obese and non-obese children. J. Pediatr. Endocrinol. Metab. 17(8):1069-75. DOI: 10.1515/JPEM.2004.17.8.1069. 
422 DiPietro, L., Dziura, J., Yeckel, C.W., Neufer, P.D. 2006. Exercise and improved insulin

423

424

425

426

427

428

429

430

432

433

434

435

436

437

438

439

440

441

442

443

444

445

446 sensitivity in older women: evidence of the enduring benefits of higher intensity training. J. Appl. Physiol. 100(1): 142-149. doi: 10.1152/japplphysiol.00474.2005.

Donges, C.E., Duffield, R., Guelfi, K.J., Smith, G.C., Adams, D.R., Edge, J.A. 2013. Comparative effects of single-mode vs. duration-matched concurrent exercise training on body composition, low-grade inflammation, and glucose regulation in sedentary, overweight, middle-aged men. Appl. Physiol. Nutr. Metab. 38(7):779-88. doi: 10.1139/apnm-2012-0443.

Dunstan, D.V., Daly, R.M., Owen, N., Jolley, D., De Courten, M., Shaw, J., et al. 2002. HighIntensity Resistance Training Improves Glycemic Control in Older Patients With Type 2 Diabetes. Diabetes Care. 25(10): 1729-1736. doi:10.2337/ diacare. 25. 10.1729 .

Fielding, R.A. 1995. The role of progressive resistance training and nutrition in the preservation of lean body mass in the elderly. J. Am. Coll. Nutr. 14(6):587-594. doi:10. 1080/07315724.1995.10718547

Fowler, N.E., Trzaskoma, Z., Wit, A., Iskra, L., Lees, A. 1995. The effectiveness of a pendulum swing for the development of leg strength and counter-movement jump performance. J. Sports. Sci. 13(2): 101-108.

Ghahramanloo, E., Midgley, A.W., Bentley, D.J. 2009. The effect of concurrent training on blood lipid profile and anthropometrical characteristics of previously untrained men. J. phys. Act. Health. 6(6): 760-766.

Joseph, A.M., Hood, D.A. 2014. Relationships between exercise, mitochondrial biogenesis and type 2 diabetes. Med Sport Sci. 60:48-61. doi: 10.1159/000357335.

Keskin, M., Kurtoglu, S., Kendirci, M., Atabek, M.E., Yazici C. 2005. Homeostasis model assessment is more reliable than the fasting glucose/insulin ratio and quantitative 
insulin sensitivity check index for assessing insulin resistance among obese children and adolescents. Pediatrics. 115(4): e500-503. doi: 10. 1542/ peds. 2004- 1921.

Koebnick, C., Shaibi, G.Q., Kelly L.A., Roberts, C.K., Lane, C.J., Toledo-Corral, C., et al. 2007. Leptin-to-adiponectin ratio as independent predictor of insulin sensitivity during growth in overweight Hispanic youth. J. Endocrinol. Invest. 30(7): RC13-16.

Lobstein, T., Jackson-Leach, R., Moodie, M.L., Hall, K.D., Gortmaker, S.L., Swinburn, B.A., et al. 2015. Child and adolescent obesity: part of a bigger picture. Lancet. 385(9986):2510-20. doi: 10.1016/S0140-6736(14)61746-3.

Masquio, D.C., de Piano, A., Campos, R.M., Sanches, P.L., Carnier, J., Corgosinho, F.C., et al. 2015. The role of multicomponent therapy in the metabolic syndrome, inflammation and cardiovascular risk in obese adolescents. Br. J. Nutr. 113(12):1920-1930. doi: 10.1017/S0007114515001129.

Mcbride, J.M., Triplett-Mcbride, T., Davie, A., Newton, R.U. 2002. The effect of heavy- vs. light-load jump squat on the development of strength, power, and speed. J. Strength. Cond. Res. 16(1):75-82.

Miller, J.P., Pratley, R.E., Goldberg, A.P., Gordon, P., Rubin, M., Treuth, M.S., et al. 1994. Strength training increases insulin action in healthy 50- to 65-yr-old men. J. Appl. Physiol. 77(3):1122-1127.

Myer, G., Ford, K., Palumbo, J., Hewitt, T. 2005. Neuromuscular training improves performance and lower extremity biomechanics in female athletes. J. Strength. Cond. Res. 19(1): 51-60.

Neu, C.M., Rauch, F., Rittweger, J., Manz, F., Schoenau, E. 2002. Influence of puberty on muscle development at the forearm. Am. J. Physiol. Endocrinol. Metab. 283(1): E103-7. doi: 10.1152/ajpendo.00445.2001. 
471 Nunez-Gaunaurd, A., Moore, J.G., Roach, K.E., Miller, T.L., Kirk-Sanchez, N.J. 2013. Motor

472 proficiency, strength, endurance, and physical activity among middle school children 473 who are healthy, overweight, and obese. Pediatr. Phys.Ther. 25(2):130-8. doi: $474 \quad$ 10.1097/PEP.0b013e318287caa3.

475 O’Brien, T.D., Reeves, N.D., Baltzopoulos, V., Jones, D.A., Maganaris, C.N. 2009. Strong 476 relationships exist between muscle volume, joint power and whole-body external mechanical power in adults and children. Exp. Physiol. 94(6):731-38. doi: 10.1113/ expphysiol.2008.045062.

O’Brien, T.D., Reeves, N.D., Baltzopoulos, V., Jones, D.A., Maganaris, C.N. 2010. In vivo 480 measurements of muscle specific tension in adults and children. Exp Physiol. 95(1):202-10. doi: 10.1113/expphysiol.2009.048967.

482

483

484

Ozmun, J.C., Mikesky, A.E., and Surburg, P.R. 1994. Neuromuscular adaptations following prepubescent strength training. Med. Sci. Sports Exerc. 26(4): 510-514. doi: $10.1249 / 00005768-199404000-00017$.

Paoli, A., Pacelli, Q.F., Moro, T., Marcolin, G., Neri, M., Battaglia, G., et al. 2013. Effects of high-intensity circuit training, low-intensity circuit training and endurance training on blood pressure and lipoproteins in middle-aged overweight men. Lipids. Health. Dis.12: 131. doi:10.1186/1476-511X-12-131.

Poehlman, E.T., Dvorak, R.V., de Nino, W.F., Brochu, M., Ades, P.A. 2000. Effects of resistance training and endurance training on insulin sensitivity in nonobese, young women: a randomized controlled trial. J. Clin. Endocrinol. Metab. 85(7): 2463-2468.

Racil, G., Ben Ounis, O., Hammouda, O., Kallel, A., Zouhal, H., Chamari, K., et al. 2013. Effects of high vs. moderate exercise intensity during interval training on lipids and adiponectin levels in obese young females. Eur. J. Appl. Physiol. 113(10): 25312540. doi: 10.1007/s00421-013-2689-5. 
496 Racil, G., Lemaire, C., Dubart, A.E., Garcin, M., Coquart, J.B. 2015. Intermittent Exercise is 497 Beneficial to Obese Women Independently of Obesity Class. J. J. Physiother. $498 \quad$ Exercise. 1(1): 003. doi: 10.13140/RG.2.1.1635.0886

499 Ramsay, J.A., Blimkie, C.J.R., Smith, K., Garner, S., MacDougall, J.D., and Sale, D.G. 1990. $500 \quad$ Strength training effects in prepubescent boys. Med. Sci. Sports. Exerc. 22(5): 605501 614. doi:10.1249/00005768-199010000-00011.

502 Rolland-Cachera, M.F., Cole, T.J., Sempé, M., Tichet, J., Rossignol, C., Charraud, A. 1991. 503 Body mass index variations: centiles from birth to 87 yearth. Eur. J. Clin. Nutr. 45: $504 \quad 13-21$.

505 Rose, AJ and Richter, EA. 2005. Skeletal muscle glucose uptake during exercise: how is it 506 regulated? Physiology 20(4): 260-270. doi: 10.1152/physiol.00012.2005.

507

508

509

510

511

512

Ryan, A.S., Pratley, R.E., Goldberg, A.P., Elahi, D. 1996. Resistive training increases insulin 513 action in postmenopausal women. J. Gerontol. A. Biol. Sci. Med. Sci. 51(5):M199-

514 Sartor, F., de Morree, H.M., Matschke, V., Marcora, S.M., Milousis, A., Thom, J.M. et al. 515 2010. High-intensity exercise and carbohydrate-reduced energy-restricted diet in

518 Serdula, M.K., Ivery, D., Coates, R.J., Freedman, D.S., Williamson, D.F., Byers, T. 1993. Do 519 obese children become obese adults? A review of the literature. Prev. Med. 22:167520 177. 
521 Shabi, G., Cruz, M., Ball, G.,Weigensberg, M., Salem, G., Crespo, N., Goran, M. 2006. Effects of resistance training on insulin sensitivity in overweight Latino adolescent males. Med. Sci. Sports. Exerc. 38(7): 1208-1215. doi: 10.1249/01. mss. 000227304 $.88406 .0 \mathrm{f}$

Whitaker, R.C., Wright, J.A., Pepe, M.S., Seidel, K.D., Dietz, W.H. 1997. Predicting obesity in young adulthood from childhood and parental obesity. N. Engl. J. Med. 37:869873.

Willis, L.H., Slentz, C.A., Bateman, L.A., Shields, A.T., Piner, L.W., Bales, C.W., et al. 2012. Effects of aerobic and/or resistance training on body mass and fat mass in overweight or obese adults. J. Appl. Physiol. 113(12):1831-1837. doi: 10.1152/japplphysiol. 01370.2011.

Yamamoto, Y., Hirose, H., Saito, I., Tomita, M., Taniyama, M., Matsubara, K., et al. 2002. Correlation of the adipocyte-derived protein adiponectin with insulin resistance index and serum height-density lipoprotein-cholesterol, independent of body mass index, in the Japanese population. Clin. Sci. 103: 137-142.

Yamauchi, T., Kamon, J., Minokoshi, Y., Waki, H., Uchida, S., Yamashita, S., et al. 2002. Adiponectin stimulates glucose utilization and fatty-acid oxidation by activating AMP-activated protein kinase. Nat. Med. 8(11):1288-1295. doi:10.1038/nm788.

Yaspelkis, B.B., Singh, M.K., Krisan, A.D., Collins, D.E., Kwong, C.C., Bernard, J.R. et al. 2004. Chronic leptin treatment enhances insulin-stimulated glucose disposal in skeletal muscle of high-fat fed rodents. Life Sci. 74(14): 1801-1816. doi:10.1016/j.lfs.2003.08.037.

Zhou, B.F. 2002. Effect of body mass index on all-cause mortality and incidence of cardiovascular diseases--report for meta-analysis of prospective studies open optimal 
cut-off points of body mass index in Chinese adults. Biomed. Environ. Sci. Sep; $15(3): 245-52$. 


\begin{tabular}{|c|c|c|c|c|c|c|}
\hline & \multicolumn{2}{|c|}{ HIIT group $(n=23)$} & \multicolumn{2}{|c|}{$\mathrm{P}+$ HIIT group $(n=26)$} & \multicolumn{2}{|c|}{ Control group $(n=19)$} \\
\hline & Pre- & Post- & Pre- & Post- & Pre- & Post- \\
\hline Age $(y)$ & $16.6 \pm 0.9$ & & $16.5 \pm 1.2$ & & $16.9 \pm 1.0$ & \\
\hline Height (m) & $1.63 \pm 0.05$ & $1.63 \pm 0.05$ & $1.63 \pm 0.02$ & $1.64 \pm 0.02$ & $1.64 \pm 0.06$ & $1.64 \pm 0.06$ \\
\hline Body mass (kg) & $83.9 \pm 4.5$ & $80.7 \pm 5.7^{*}$ & $82.5 \pm 5.4$ & $80.8 \pm 5.0 *$ & $81.8 \pm 5.2$ & $81.3 \pm 4.9$ \\
\hline Body mass index $Z$-score & $2.9 \pm 0.2$ & $2.4 \pm 0.3^{*}$ & $2.9 \pm 0.3$ & $2.6 \pm 0.2 *$ & $2.8 \pm 0.3$ & $2.7 \pm 0.3$ \\
\hline Body fat (\%) & $39.3 \pm 1.7$ & $36.5 \pm 1.3^{*}$ & $41.7 \pm 3.6$ & $38.8 \pm 3.7 *$ & $36.7 \pm 2.0$ & $37.0 \pm 1.9$ \\
\hline Lean body mass $(\mathrm{kg})$ & $50.9 \pm 2.9$ & $51.2 \pm 3.8$ & $48.2 \pm 5.6$ & $49.6 \pm 5.7 * 8$ & $51.7 \pm 3.1$ & $51.3 \pm 3.2$ \\
\hline Waist circumference $(\mathrm{cm})$ & $93 \pm 5$ & $90 \pm 6^{*}$ & $94 \pm 5$ & $90 \pm 4 *$ & $93 \pm 4$ & $92 \pm 3$ \\
\hline Plasma glucose $\left(\mathrm{mmol.1} \mathrm{l}^{-1}\right)$ & $4.8 \pm 0.5$ & $4.6 \pm 0.4 *$ & $4.6 \pm 0.5$ & $4.1 \pm 0.4^{\# \S}$ & $4.7 \pm 0.3$ & $4.8 \pm 0.4$ \\
\hline Plasma insulin $\left(\mu \mathrm{U} \cdot \mathrm{ml}^{-1}\right)$ & $21.1 \pm 2.4$ & $15.6 \pm 1.2^{\#}$ & $20.8 \pm 1.8$ & $14.6 \pm 1.0^{\# \mathfrak{E}}$ & $19.2 \pm 2.0$ & $18.6 \pm 1.6$ \\
\hline Homeostasis model assessment-insulin resistance & $4.5 \pm 0.7$ & $3.2 \pm 0.4^{\#}$ & $4.3 \pm 0.6$ & $2.7 \pm 0.3^{\phi \S}$ & $4.1 \pm 0.6$ & $4.0 \pm 0.5$ \\
\hline Plasma leptin (ng.ml $\left.{ }^{-1}\right)$ & $20.2 \pm 2.6$ & $17.3 \pm 1.8 *$ & $17.6 \pm 2.3$ & $13.5 \pm 2.0 * \S$ & $18.5 \pm 2.0$ & $18.9 \pm 1.8$ \\
\hline Plasma adiponectin $\left(\mu \mathrm{g} . \mathrm{ml}^{-1}\right)$ & $7.5 \pm 1.5$ & $9.4 \pm 1.7 *^{\mathfrak{f}}$ & $8.0 \pm 1.3$ & $10.5 \pm 1.7^{* \mathfrak{f}}$ & $7.1 \pm 1.1$ & $7.4 \pm 0.7$ \\
\hline Plasma leptin/adiponectin ratio & $2.8 \pm 0.6$ & $1.9 \pm 0.4^{\#}$ & $2.3 \pm 0.5$ & $1.3 \pm 0.3^{\phi \S}$ & $2.7 \pm 0.6$ & $2.6 \pm 0.3$ \\
\hline Peak oxygen uptake $\left(\mathrm{ml} \cdot \mathrm{kg}^{-1} \cdot \mathrm{min}^{-1}\right)$ & $36.7 \pm 1.1$ & $39.2 \pm 1.0^{\#}$ & $36.0 \pm 1.7$ & $39.4 \pm 1.8^{\#}$ & $38.3 \pm 1.4$ & $38.8 \pm 1.5$ \\
\hline Velocity at peak oxygen uptake $\left(\mathrm{km} \cdot \mathrm{h}^{-1}\right)$ & $10.1 \pm 0.8$ & $11.2 \pm 0.9 *$ & $9.8 \pm 0.7$ & $10.9 \pm 0.7 *$ & $10.2 \pm 0.4$ & $10.4 \pm 0.7$ \\
\hline Performance in squat jump $(\mathrm{cm})$ & $17.9 \pm 2.3$ & $19.7 \pm 2.4^{*}$ & $17.1 \pm 2.5$ & $20.8 \pm 2.2^{\# \mathfrak{E}}$ & $18.1 \pm 1.5$ & $18.4 \pm 1.4$ \\
\hline Performance in countermovement jump $(\mathrm{cm})$ & $18.9 \pm 2.7$ & $21.2 \pm 2.9^{*}$ & $18.8 \pm 2.7$ & $22.5 \pm 2.6^{\#}$ & $20.2 \pm 2.0$ & $20.6 \pm 2.6$ \\
\hline Energy intake $\left(\mathrm{kcal} . \mathrm{d}^{-1}\right)$ & $3002 \pm 107$ & $2900 \pm 93$ & $2888 \pm 96$ & $2812 \pm 92$ & $2945 \pm 96$ & $2904 \pm 99$ \\
\hline
\end{tabular}

Table 1. Anthropometric, biochemical, and physical fitness data and energy intake (mean \pm standard deviation) pre- and post-intervention

program, in HIIT (high-intensity interval training), $\mathrm{P}+\mathrm{HIIT}$ (plyometric exercises combined with HIIT) and control groups.

Significantly different within each group before $v s$ after the intervention program *: $P<0.05,{ }^{\#}: P<0.01,{ }^{\Phi}: P<0.001$. Significantly different from control ${ }^{\mathfrak{E}}: P<0.05$. Significantly different from the other groups ${ }^{\S}: P<0.05$. 


\begin{tabular}{|c|c|c|c|}
\hline & HIIT group $(n=23)$ & P+HIIT group $(n=26)$ & Control group $(n=19)$ \\
\hline Body mass & $-3.8 \pm 3.9^{\ddagger}$ & $-2.0 \pm 1.0^{f}$ & $-0.6 \pm 1.6$ \\
\hline Body mass index $Z$-score & $-15.9 \pm 4.8^{\mathfrak{f}}$ & $-9.6 \pm 2.6^{\mathfrak{t}}$ & $-3.7 \pm 2.3$ \\
\hline Body fat & $-7.1 \pm 1.7^{\mathfrak{f}}$ & $-7.2 \pm 1.8^{\mathfrak{f}}$ & $0.6 \pm 0.9$ \\
\hline Lean body mass & $0.6 \pm 4.4$ & $3.0 \pm 1.7^{\S}$ & $-0.9 \pm 1.5$ \\
\hline Waist circumference & $-3.2 \pm 2.2^{\mathfrak{f}}$ & $-4.0 \pm 1.0^{£}$ & $-0.6 \pm 1.0$ \\
\hline Plasma glucose & $-3.4 \pm 1.2^{\mathfrak{E}}$ & $-11.0 \pm 4.7^{\S}$ & $1.3 \pm 3.5$ \\
\hline Plasma insulin & $-25.8 \pm 5.9^{\mathfrak{f}}$ & $-29.5 \pm 5.6^{\mathfrak{t}}$ & $-3.2 \pm 3.2$ \\
\hline Homeostasis model assessment-insulin resistance & $-28.3 \pm 5.8^{\mathfrak{f}}$ & $-37.3 \pm 6.2^{\S}$ & $-2.0 \pm 2.8$ \\
\hline Plasma leptin & $-14.0 \pm 5.4^{\mathfrak{f}}$ & $-23.8 \pm 5.8^{\S}$ & $3.0 \pm 10.3$ \\
\hline Plasma adiponectin & $27.3 \pm 20.7^{\mathfrak{x}}$ & $32.8 \pm 20.6^{\mathfrak{E}}$ & $5.7 \pm 12.1$ \\
\hline Plasma leptin/adiponectin ratio & $-31.3 \pm 8.9^{\mathfrak{f}}$ & $-40.9 \pm 10.9^{\S}$ & $-0.8 \pm 18.8$ \\
\hline Peak oxygen uptake & $7.0 \pm 2.2^{\mathfrak{f}}$ & $9.5 \pm 3.0^{\mathfrak{f}}$ & $1.2 \pm 1.5$ \\
\hline Velocity at peak oxygen uptake & $10.9 \pm 4.8^{\mathfrak{E}}$ & $11.7 \pm 6.0^{\mathfrak{f}}$ & $2.1 \pm 3.2$ \\
\hline Performance in squat jump & $10.4 \pm 3.8^{\mathfrak{E}}$ & $22.2 \pm 7.5^{\S}$ & $1.4 \pm 1.9$ \\
\hline Performance in countermovement jump & $11.8 \pm 4.2^{\mathfrak{f}}$ & $20.0 \pm 10.2^{\mathfrak{E}}$ & $1.7 \pm 3.6$ \\
\hline Energy intake & $-3.4 \pm 2.4$ & $-2.6 \pm 1.7$ & $-1.4 \pm 1.6$ \\
\hline
\end{tabular}

Table 2. Percentage changes in anthropometric, biochemical, physical fitness data and energy intake (mean \pm standard deviation) after the intervention program, in HIIT (high-intensity interval training), P+HIIT (plyometric exercises combined to HIIT) and control groups.

Significantly different from control ${ }^{\mathfrak{1}}: P<0.05$. Significantly different from the other groups ${ }^{\S}: P<0.05$. 
Captions of tables.

Table 1. Anthropometric, biochemical, and physical fitness data and energy intake (mean \pm standard deviation) pre- and post-intervention program, in HIIT (high-intensity interval training), P+HIIT (plyometric exercises combined with HIIT) and control groups.

Significantly different within each group before $v s$ after the intervention program $*: P<0.05,{ }^{\#}: P<0.01,{ }^{\Phi}: P<0.001$. Significantly different from control ${ }^{\mathfrak{E}}: P<0.05$. Significantly different from the other groups ${ }^{\S}: P<0.05$.

Table 2. Percentage changes in anthropometric, biochemical, physical fitness data and energy intake (mean \pm standard deviation) after the intervention program, in HIIT (high-intensity interval training), P+HIIT (plyometric exercises combined to HIIT) and control groups.

Significantly different from control ${ }^{\mathfrak{f}}: P<0.05$. Significantly different from the other groups ${ }^{\S}: P<0.05$. 